\title{
Ríos de ideas
}

José Luis Gómez Ordóñez Docente, Universidad de Granada

Un viaje a Santiago del autor entrega una experiencia de recorrido de la ciudad y del río Mapocho, que muchas veces no somos capaces de ver y comprender. La existencia de una particular topografía y del cauce del río son determinantes de un paisaje, una trama urbana compleja y de situaciones particulares que enriquecen la ciudad.

En general, las ciudades asentadas en las riberas de los ríos han nacido de la construcción de un puente que atraviesa ese obstáculo a la circulación terrestre y de la fricción con la navegación fluvial. La intersección de la geografía con la infraestructura marca el origen y la evolución de las ciudades que, como nos ha enseñado Marcel Pöete, nacen del camino, fertilizadas por los flujos de personas, bienes e ideas.

También hay ciudades, como Santiago de Chile, que se fundan junto a un curso de agua por la disponibilidad de este recurso para su consumo y el riego de los campos de cultivo aledaños y para facilitar el drenaje de las aguas de lluvia. En estos casos es, básicamente, un asunto de pendientes y topografía el que dicta el emplazamiento de la ciudad en el valle: acequias, canales de riego, caudales de avenidas - con su aportación de nutrientes según líneas paralelas al cauce-y drenajes según líneas de máxima pendiente, perpendiculares al mismo.

Santiago, en la falda andina, entrecruzó así las dos direcciones de su cuadrícula fundacional, que encuentra en las emergencias de los cerros el respaldo defensivo y la presencia paisajística que singulariza el emplazamiento. Ciudades como Santiago y tantas del Mediterráneo europeo han tenido en sus ríos sus límites urbanos y han inscrito su relieve en una geografía sin infraestructura de puente o vía de navegación.

Cuando las inmensas cuadrículas de las grandes ciudades sudamericanas cruzan el río rebasando aquella limitación topográfica, el tráfico urbano sustituye a la escorrentía de las aguas, que sólo en sus desbordamientos cíclicos y en sus muros defensivos recuerdan su condición fluvial. El crecimiento urbano transforma el río de límite en barrera a salvar. Como aprendimos en nuestro proyecto para el Genil en Granada, el río, que no fue puenteado para construir la ciudad, deberá serlo para su extensión a la otra ribera; y lo que era mero desagüe necesitará ser elemento importante en la canalización de movimientos, tanto longitudinales como transversales. A la geografía urbana le sobrevendrá la infraestructura.

Si la Carretera Panamericana atraviesa Santiago de norte a sur, en reconocimiento de la forma alargada del país, los cauces del río Mapocho y del zanjón de la Aguada lo perforan de este a oeste, reflejando el emplazamiento de la ciudad en la falda de los Andes y su mirada al Pacífico. Si las encrucijadas orientan a cuatro infinitos - dijo Borges de Buenos Aireslas de Santiago son asimétricas: las horizontales - oriente-poniente- son más locales, más intensas en sus relaciones cortas y urbanas; las verticales -norte-sur-son más de paso, más orientadas a relaciones largas.

La elipse de Avenida Américo Vespucio y el Plan Regulador Intercomunal de 1960 suponen la circunvalación de la retícula de vías ortogonales y obliga, a partir de su existencia, a que la construcción de los episodios de urbanidad del Gran Santiago consistan en la cuadratura del círculo, en reconstruir referencias ortogonales de latitud general y longitud local, tratando de complementarlas, añadiendo localismo a las verticales y jerarquía y pluricomunalidad a las horizontales.

Y, entre las horizontales, nada como el río Mapocho expresa la urbanidad plural y multiescalar del Gran Santiago. A lo largo de una treintena de kilómetros una docena de comunas, desde Lo Barnechea a Renca en la
An author's trip to Santiago offers an experience of the city's and Mapocho River's promenade, which we are often not able to see and understand. The existence of a particular topography and a river bed are the determinants of landscape, a complex urban scheme, and the particular situations that enrich the city.

ribera norte y desde Las Condes a Maipú en la sur, encuentran en el río una referencia común y miran, o desearían mirar, al cauce como su lugar central y su puerta a la metrópolis, como una nueva plaza de mercado para cada comuna, que fuese tanto condensación interior de urbanidad como intercambio y exterioridad intercomunal.

El río Mapocho, que fue límite norte de la ciudad fundacional, aún hoy en la metrópolis extensa asienta, en su ribera norte, menos ciudad que al sur, aunque es rigurosamente central en el tramo entre Vespucio y la Alameda Bernardo O’Higgins. La fuerza de la Panamericana y el ferrocarril estiran la metrópolis, mientras que las dos alas del río de esa Y que componen con Vicuña Mackenna los dos tramos fluviales a ambos lados de Plaza Baquedano, bloquean las continuidades viarias horizontales, que articularían las comunas orientales de la margen sur: Las Condes, Vitacura y Providencia, con las de Recoleta e Independencia en la ribera norte.

Pero esta relación, de la que la Avenida Kennedy sería una clara expresión viaria, está obstruida por el cerro San Cristóbal, de manera que aquella conexión horizontal, que atravesaría las márgenes de un Mapocho diagonal, se escurre y concentra en los límites norte y sur del San Cristóbal, sea mediante la circunvalación Américo Vespucio o por la Costanera Norte. Y como Avenida Vespucio está a cinco kilómetros al norte del Mapocho -tomando distancia en el vértice de Baquedano-, los flujos intercomunales y metropolitanos oriente-poniente buscan en mayor medida la Avenida Costanera, como alternativa veloz y alivio de la congestionada Alameda Bernardo O’Higgins.

Por eso es tan razonable pensar en una perforación de un túnel bajo el cerro San Cristóbal, que diese continuidad a Avenida Kennedy (después de faldear el zócalo oeste del cerro), con avenidas como Domingo Santa María, Einstein y Dorsal, intensificando la relación y disminuyendo el sentimiento de distancia física y social entre las comunas de Vitacura y Providencia de una margen y Recoleta de la otra; y disminuyendo esa excesiva fricción de las riberas del río, en gran parte debida a la lejanía del by-pass de A. Vespucio. Una idea que coincide plenamente con la propuesta del arquitecto Mario Pérez de Arce (1997), que es bien diferente de la del Plan Regulador Intercomunal, desarrollada en el plan de Transporte Metropolitano de 1974, que perfora el cerro San Cristóbal de sur a norte, desde la obsesión por construir anillos circulares sobre la cuadrícula.

En efecto, cabría corresponder en la margen norte a las grandes vías verticales, dando continuidad a las de la otra margen, en el sur: Avenida Perú y El Salto, Independencia, Fermín Vivaceta, la Panamericana, el ferrocarril -qué estupenda dotación y ubicación de esas estaciones suburbanas, Renca, Huamache y Lo Ruiz-, con nuevas continuidades horizontales, hoy interrumpidas por el cerro San Cristóbal, pero también por los cementerios y por el cerro Blanco y el Hipódromo, así como por la zona industrial contigua a la línea férrea.

Así, tenemos planteado el conflicto: un río Mapocho con alto potencial de representación metropolitana, en su pluralidad comunal, sometido a una intensa fricción de tráficos veloces y de recorridos largos en sentido oriente-poniente. Tráficos que la circunvalación Américo Vespucio, en su 


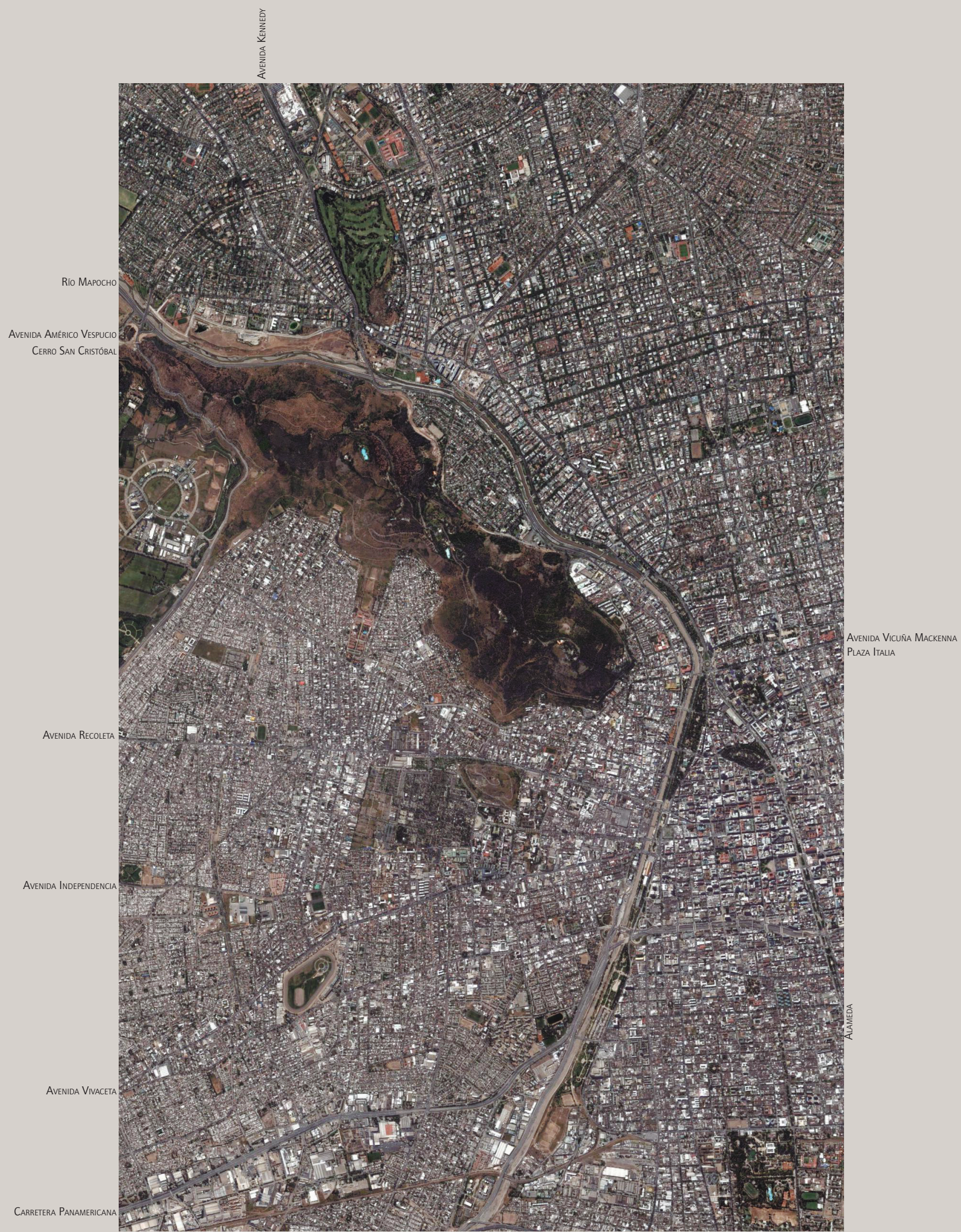

01 Río Mapocho entre Avenida Presidente Kennedy y la Carretera Panamericana, Santiago. Fuente: Servicio de imágenes del planeta Google Earth ${ }^{\top M}$ 


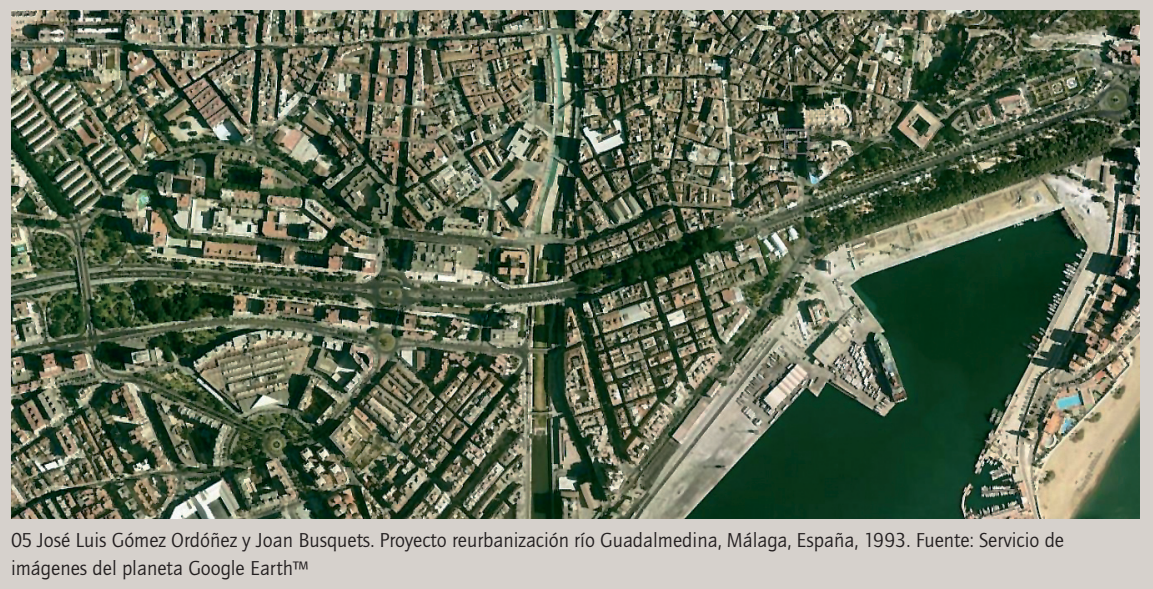

parte norte, se ve incapaz de captar, al menos en la intensidad requerida para tranquilizar el corredor fluvial, sobre todo, por su trazado inhábil para canalizar los viajes de media distancia, de entre diez y veinte kilómetros de longitud. Sin esta disminución del tráfico es muy difícil que este corredor pueda ser, acorde con su excepcional geografía, la más importante calle amable del Gran Santiago.

Habría de tomar en consideración a este respecto que hoy muchas ciudades en el mundo están elaborando planes y proyectos para cambiar la función de canales de tráfico, de vías arteriales, de algunas de sus grandes calles, por la de corredores de actividad, en el desarrollo de aquella idea que arranca de Jacobs y que formula posteriormente Appleyard con sus Livable streets; esas calles en las que puedan coexistir diferentes modos de transporte, diferentes actividades, diversidad de flujos y ritmos de movimiento. En el caso de que esta gran calle coincida con una matriz geográfica tan marcada, como es el caso de Santiago y su río, es claro que la transformación debería considerar la potenciación de la dimensión natural; convertirla en un elemento de la red ecológica de la metrópolis. Quizás muchos proyectos en el entorno fluvial deberían contar con este cambio futuro de la circulación en sus riberas.

Cabe encontrar en el cauce del Mapocho, en su condición de horizontal común a doce comunas, el más claro elemento de la estructura metropolitana de espacios libres: un corredor natural que evoca y ofrece la presencia imponente de los Andes y que nos hace sentir, apostados en cualquiera de sus puentes o lugares de sus riberas, inmersos en esa corriente de la vida, en esa historia del infinito, que para Elisée Réclus -en su espléndido libro El Arroyo- supone cualquier río.

Esa condición natural del Mapocho, perturbada por el intenso tráfico de sus riberas y por el hormigón de sus paredones, obliga a buscar sus adherencias locales y la articulación de sus episodios comunales en una secuencia metropolitana; quizás, en algunos lugares y en un futuro no muy lejano pudiera pensarse en una renaturalización, en el derribo de los muros de encauzamiento sin merma de las garantías de seguridad frente a las avenidas, para recuperar una continuidad del cauce con su ribera inmediata.

Podría pensarse igualmente en la supresión o atenuación de la circulación automotriz en el borde mismo del muro de encauzamiento, en aquellos tramos en que ello parece posible, al disponer de una calzada paralela, inmediata pero no contigua, al cauce: transferir los tráficos -una vez atenuados por un desvío modal al transporte público, que no se trata de mejorar el río para agobiar las calles interiores- de calles como José María Caro a Ismael Valdés Vergara o de Santa María a Bellavista. De esta manera, se religarían los parques y riberas arboladas con el cauce, enriqueciendo el disfrute del parque con el goce sensorial del agua.

Cada tramo comunal del río podría encontrar la manera de difundir esa condición natural de la ribera, a través de algunas de sus calles perpendiculares al cauce, peatonalizándolas y cargándolas de usos colectivos, enlazando el verde de ribera con el de algunas placitas, equipamientos y lugares cívicos más notables. Cada comuna podría así contribuir al valor natural colectivo con su particular puerta al río, enhebrando, a lo largo de ambas riberas con la mayor continuidad y diversidad posibles, una secuencia lineal metropolitana de parques, museos, miradores, centros cívicos y monumentos. Con esto podría disminuir la segregación creciente entre barriadas centrales y periféricas, opulentas y humildes. Nuevos puentes - actualmente grandes y fuera del centro, con excesivas distancias entre ellos-, sobre todo peatonales y para el transporte público, podrían enriquecer esa secuencia lineal con una mayor articulación entre los episodios de ambas riberas.

En las secuencias siempre hay lugares de una mayor significación, de un más grande simbolismo; en el caso del río Mapocho, qué duda cabe de que la encrucijada de la traza en $Y$ en Baquedano es uno de ellos: ahí, en Plaza Italia confluyen los parques de ribera Forestal y Gran Bretaña con el vertical de Bustamante; los cerros de Santa Lucía y San Cristóbal, la confluencia de las avenidas Vicuña Mackenna, Alameda Bernardo O’Higgins y Providencia, así como el cruce central de líneas de Metro y autobús. Todos ellos otorgan una extraordinaria centralidad y significado a ese lugar, haciendo del mismo un sensible laboratorio para buenas prácticas de diseño urbano, para la elaboración de proyectos que atendiesen de manera prioritaria al confort y continuidad de las movilidades lentas en el disfrute del río, de sus parques ribereños y museos. Y quizás se pudieran extender esas buenas prácticas de reconfiguración del espacio público a una serie de intervenciones de acupuntura urbana, que articulasen un sistema central de parques y espacios públicos, enlazando a través de calles tranquilas los parques Quinta Normal, O’Higgins, Almagro y Bustamante con los parques de ribera como el de los Reyes y Forestal. 


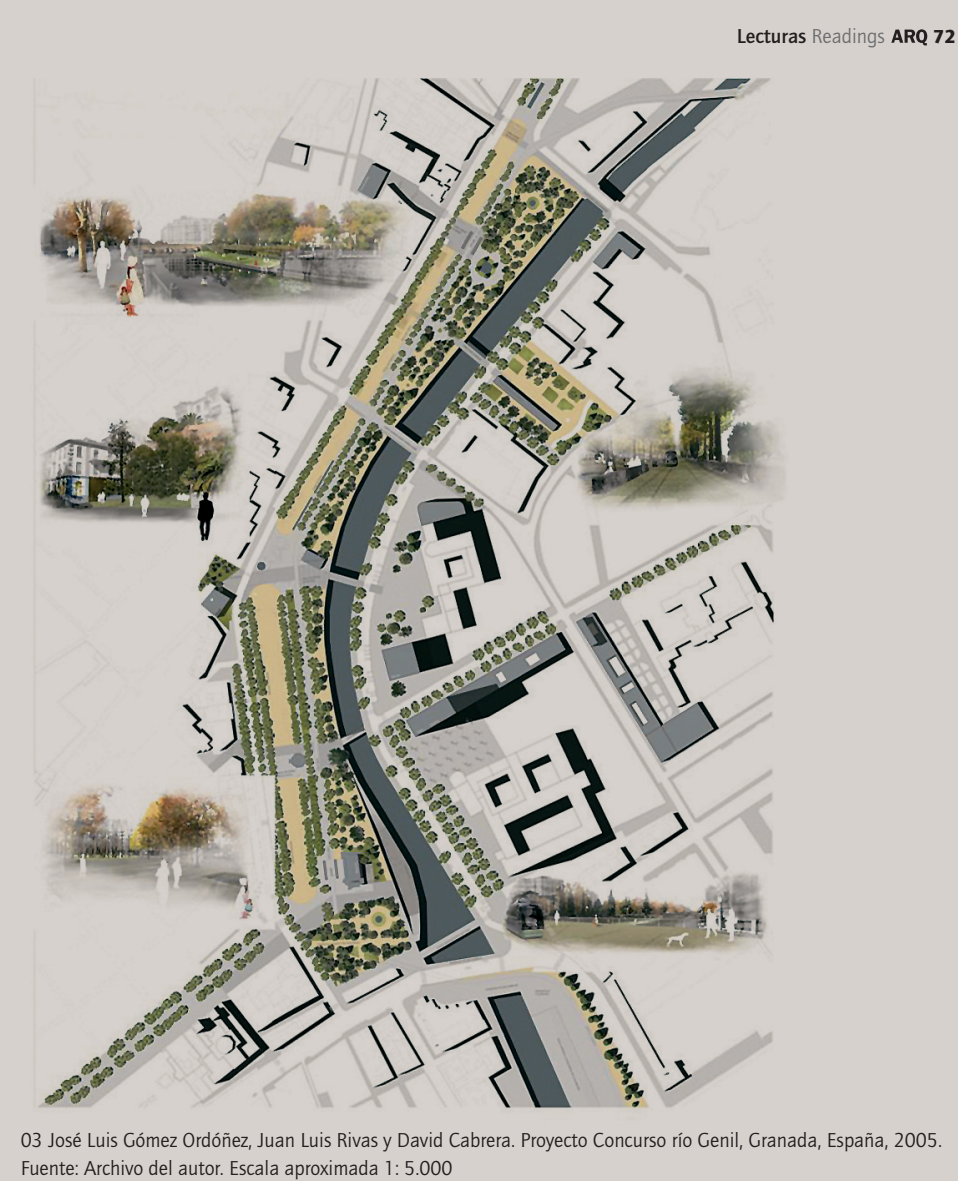

Otros focos potenciales de atención también importantes se presentan en las intersecciones viarias de Américo Vespucio y la Panamericana con el cauce y en las riberas de la periferia occidental, en el área de Pudahuel y Maipú, en ese poniente donde el Gran Santiago debería, quizás, encontrar otro de sus grandes parques de escala metropolitana, como el cerro San Cristóbal.

La intensificación en los últimos veinte años de las razones ambientales, otorgando continuidad y permanencia a una de las corrientes más vigorosas del urbanismo, está informando en nuestras grandes ciudades. Se han generado espléndidas prácticas proyectuales y de planificación, teniendo los entornos fluviales un fuerte protagonismo en ellas.

En este sentido habría que dirigir, para terminar, una ligera mirada a Europa. Específicamente a los ríos de dos grandes ciudades: Londres y París. En ambas, con la Jubilee Line y la Meteor, se han construido dos lineas fundamentales del metro, posibilitando la descarga de tráfico automovilístico en sus arterias ribereñas. Por lo demás, en Londres el río Támesis ha tenido siempre un fuerte protagonismo en su imagen de metrópolis mundial: desde la Custom House y las Parliament' Houses, el proyecto neoclásico Adelphi de los hermanos Adams, pasando por el Royal Festival Hall y la reconversión de los Docklands, hasta las intervenciones recientes del Milenio, la nueva Tate Modern, la cúpula y el puente de Foster y muchos de los previstos cien proyectos para el Londres del ex alcalde Livingstone, que tenían su objetivo de mejora cívica en lugares del cauce, descargados de su vieja condición portuaria. Obsérvese también la circulación moderada o excluida en las riberas de Kensington, Chelsea, Westminster y la City, en la margen izquierda, en muelles como el Victoria Embankment. La planificación regional al este de Londres se articula en un área denominada Thames Gateway y las instalaciones para los próximos Juegos Olimpícos regenerarán el Lee Valley, un afluente del Támesis.

En París, la planificación metropolitana vigente considera el corredor del Sena como lugar preferente para su descentralización policéntrica y como el gran eje verde de la ciudad-región, articulando no sólo centros productivos sino lugares de ocio, de depósito de la memoria histórica y de valor patrimonial. En el París metropolitano, nuevas centralidades como la de Bercy-Tolbiac - con la biblioteca de Francia, la nueva estación de Austerlitz, parques, viviendas, ministerios y una importante actividad uni-

versitaria-, asumen la necesidad de compensar a oriente, de manera más civilizada, la carga del centro terciario de la Défense de los años setenta y de seguir, aún en la ciudad central, asumiendo la responsabilidad icónica de las riberas del Sena como asentamiento de los lugares de mayor carga simbólica de la ciudad. Y, sin embargo, la circulación de las riberas está lejos de la intensidad que le otorgaría su condición arterial metropolitana, gracias a la implantación de la citada línea oriente-poniente del metro exprés regional.

Finalmente, cito los casos de dos ciudades españolas, Granada y Málaga, en Andalucía, donde he trabajado en la reurbanización de sus cauces fluviales, el Genil y el Guadalmedina respectivamente, en sendos proyectos. El primero fue realizado para un concurso de ideas, en colaboración con los arquitectos Juan Luis Rivas y David Cabrera, pretendiendo tejer sinapsis que irradiasen al conjunto de la ciudad desde un cauce, transformado de límite a centro, con nuevas actividades en sus riberas. El segundo, en colaboración con el arquitecto Joan Busquets, fue construido en 1993, generando media docena de puentes, bajando el nivel del cauce, con entrada del agua del mar en el tramo final, proponiendo una nueva fachada urbana y disponiendo la circulación automóvil en túnel, bajo una calle peatonal elevada, contigua al río.

Recorrer los ríos es siempre una buena manera de pensar las ciudades, soñarlas a la espera de hacerlas mejores, como nos enseñaba William Morris a mediados del s. XIX, pensando ya entonces el Londres del Milenio, en su News from Nowhere. Y es que, como alguien ha dicho, las ciudades son jardines de ideas y así también los ríos de las ciudades, tan implicados en su forma urbana desde sus inicios, tan expresivos de la intersección entre su geografía y su historia, entre lugar e infraestructuras: a ellos bien pueden atribuirse este rol sugerente de viveros generadores de ideas para las ciudades.

Escrito en Granada en enero de 2009, desde el afectuoso recuerdo de mi estancia en la Facultad de Arquitectura de la Pontificia Universidad Católica de Chile, en la casa de Lo Contador. ARQ

\section{Bibliografía}

Pérez de Arce, Mario. “La ciudad y la geografía”. ARQ № 37. Ediciones ARQ Santiago, noviembre de 1997. 